\title{
Effect of Intracellular and Extracellular Mushroom Polysaccharides on Growth Inhibition of Human Carcinoma Cell Lines
}

\author{
Diana Martinho ${ }^{1}$ and Amin Karmali ${ }^{1,2, *}$
}

\author{
${ }^{1}$ Chemical Engineering and Biotechnology Research Center and Department of Chemical Engineering of \\ Instituto Superior de Engenharia de Lisboa, Rua Conselheiro Emídio Navarro No.1, 1950-072 Lisboa, \\ Portugal \\ ${ }^{2}$ Centre for the Research and Technology for Agro-environmental and Biological Sciences, Universidade de \\ Trás-os- Montes e Alto Douro Quinta dos prados, Apartado 1013, 5001-801 Vila Real, Portugal
}

\begin{abstract}
Introduction: Mushroom polysaccharides play an important role in nutraceutical and functional food because they act as biological active modifiers. The aim of the present work involved the production, purification and partial characterization of intracellular (IPS) and extracellular polysaccharides (EPS) from several basidiomycete strains. Such polysaccharides were used to investigate their effect on growth of human carcinoma cell lines.

Methods: Mushroom polysaccharides were produced from several basidiomycete strains by submerged and solid state fermentations, assayed for superoxide radical scavenging activity, purified by gel filtration chromatography, analysed by FTIR and their effect on human carcinoma cell line was investigated by MTT method.

Results: Mushroom polysaccharides have revealed scavenging activity in the range of $22-81 \%$ for Po (s) and Pe (2), respectively. FTIR analysis of polysaccharides showed absorption bands characteristics of these biological macromolecules. IPS inhibited cell growth of $\mathrm{HeLa}$ in the range of $16.8-27.01 \%$ for Po (s) and Ga (1), respectively.

EPS inhibited cell growth of HeLa, A459, A431 and OE21 in the ranges of $3.08-92.2 \%, 13.8-97.4 \%, 14.7-93.8 \%$ and $25-94 \%$ for II (1) and Ga (1), Gc (1) and Ga (1), II (1) and Ga (1), Le (1) and Ga (1), respectively.

Purified preparations of polysaccharides confirmed the growth inhibition of these biomolecules.

Conclusion: The present results strongly suggest growth inhibition of human carcinoma cell lines by mushroom polysaccharides and it will require a future research to understand its molecular mechanism of action.
\end{abstract}

Keywords: Polysaccharides from basidiomycete strains, submerged and solid state fermentation, FTIR, gel filtration chromatography, Superoxide radical scavenging and cell growth inhibition activities, human carcinoma cell lines.

\section{INTRODUCTION}

Basidiomycete mushroom strains have been known since ancient times to grow on agro-industrial wastes producing high value products such as enzymes, polysaccharides, lectins, vitamins, lipids and several secondary metabolites [1]. Among these biomolecules, polysaccharides have been shown to play a major role as biological response modifiers (BRM) in several clinical disorders such as cardiovascular, HIV, diabetes, cancer, neurological and immunological disorders [2,3]. Traditional Chinese Medicine (TCM) has been used for many thousands of years to treat several disorders in Asian populations and more recently in western countries [4,5]. TCM compositions are very complex since they contain several biomolecules such as polysaccharides, saponins, flavonoids, polyphenols, and polypeptides [5]. Mushroom polysaccharides are one of the most

${ }^{*}$ Address correspondence to this author at the Chemical Engineering and Biotechnology Research Center of Instituto Superior de Engenharia de Lisboa. Rua Conselheiro Emídio Navarro, 1, 1959-007 Lisboa, Portugal; Tel: 00-351218317052; Fax: 00-351-218317267; E-mail: akarmali@deq.isel.ipl.pt important bioactive molecules of TCM compositions such as Cordiceps sinensis, Ganoderma lucidum, Lentinula edodes and Hericium erinacius [4,5]. On the other hand, complementary and alternative medicines (CAMs) have also exploited the use of mushrooms which are widely used for treatment of several diseases [6]. The bioactive substances of mushrooms in CAMs are polysaccharides which play crucial roles as immunomodulators in cancer immunotherapy [6].

Basidiomycete mushroom strains produce a heterogeneous mixture of several polysaccharides of different sizes, structures and either bound to proteins or in free forms [7]. On the other hand, several published reports have highlighted that the production of mushroom polysaccharides is dependent on several factors such as microbial strain, nature of fermentation media, growth conditions and submerged or solid state fermentation $[8,9]$. The purification of such polysaccharides in homogeneous preparations is of crucial interest to investigate their structure-function relationship $[5,6,10,11]$. Although intracellular and extracellular polysaccharides (IPS and EPS, 
respectively) from mushrooms have exhibited important medicinal properties, there are only two reports in the literature about the cytotoxic activity of purified polysaccharides from Pleurotus ostreatus on human carcinoma cell lines $[12,13]$. Moreover, there are also few reports about physico-chemical properties of mushroom polysaccharides from some basidiomycete strains mentioned in this work such as FTIR and superoxide anions scavenging activity $[10,14]$. As far as the literature is concerned, there are no reports on growth inhibition effects of all mushroom polysaccharide strains described in the present work. On the other hand, the present work investigated several substrates for production of mushroom IPS and EPS both in submerged and solid state fermentation since different and novel polysaccharides may be obtained [15]. Regarding the literature, there are no reports about the effect of all these mushroom polysaccharides on all these four human carcinoma cell lines HeLa, A459, A431 and OE21. Therefore, the aim of this work consists of production of these polysaccharides from several basidiomycete strains grown by solid state and submerged fermentation. Subsequently, such polysaccharides will be purified and partially characterized regarding their physicochemical properties. Purified polysaccharides will be used to investigate their effect on growth of human carcinoma cell lines in vitro.

\section{MATERIALS AND METHODS}

\section{Materials}

Potato Dextrose Agar (PDA) medium and yeast extract were purchased from Oxoid (Hampshire, England). Milk whey was supplied from a local manufacturer. Glucose, benzamidine, phenol, Coomassie Blue G-250, urease, xanthine, phenazine methosulphate (PMS) and nitro-blue tetrazolium (NBT) were supplied by Sigma Chemical Company (S. Louis, MO, USA). Sephacryl S-300HR was purchased from Amersham Biotech (Sweden). Hemoglobin, 3-(4,5 dimethylthiazol-2-yl)-2,5-diphenyltetrazolium bromide (MTT), peroxidase and xanthine oxidase were obtained from Biozyme Laboratories (Gwent South Wales, UK).

Human carcinoma cell lines HeLa (Cervix), A549 (Lung), A431 (Epidermis) and OE21 (Oesophagus) were obtained from European Collection of Cell Cultures (ECACC). The following basidiomycete strains were obtained from ATCC (USA) and CBS-KNAW (The Netherlands): Bjerkandera adusta ATCC $®$ MYA-263 ${ }^{\mathrm{TM}}$ (Ba) Ganoderma applanatum ATCC $\AA 32586^{\mathrm{TM}}(\mathrm{Ga})$,
Ganoderma carnosum CBS 561.96 (Gc), Irpex lacteus ATCC $® \quad 44428^{\mathrm{TM}}$ (II) Lentinula edodes ATCC ${ }^{\circledR}$ $28760^{\mathrm{TM}}$ (Le) Piptoporus betulinus ATCC $\circledast 62783^{\mathrm{TM}}$ $(P b)$, Pleurotus eryngii ATCC $\circledast 36047^{\mathrm{TM}}(P e)$, and Pleurotus ostreatus ATCC $\AA 56761^{\mathrm{TM}}$ (Po). Straw, wheat and rice husks were supplied by UTAD (Vila, Real, Portugal). All other reagents used were of analytical grade.

\section{Production of Polysaccharides from Mushroom Strains by Submerged Fermentation}

Mushroom strains (i.e Bjerkandera adusta, Ganoderma applanatum, Ganoderma carnosum, Irpex lacteus, Lentinula edodes, Piptoporus betulinus, Pleurotus ostreatus and Pleurotus eryngii) were grown in potato dextrose agar medium at $25^{\circ} \mathrm{C}$ and subsequently, they were transferred into liquid seed culture medium. The culture was grown in $500 \mathrm{~mL}$ flasks containing $100 \mathrm{~mL}$ of culture medium as follows: Boiled wheat water with $40 \mathrm{~g} \mathrm{~L}-1$ of glucose and $5 \mathrm{~g} \mathrm{~L}$ 1 of yeast extract at $\mathrm{pH} 6$ (Medium 1). Boiled wheat water with $40 \mathrm{~g} \mathrm{~L}-1$ of glucose and $5 \mathrm{~g} \mathrm{~L}-1$ of tomato pomace at $\mathrm{pH} 6.0$ (Medium 2). The culture was grown in an orbital shaker at $25^{\circ} \mathrm{C}$ and $150 \mathrm{rpm}$ for a week. The culture content was then transferred to a $2 \mathrm{~L}$ Erlenmeyer flasks containing $500 \mathrm{~mL}$ of the same culture medium for production purposes. The culture was grown for another week under the same experimental conditions.

\section{Production of Polysaccharides from Mushroom Strains by Solid State Fermentation}

$100 \mathrm{gm}$ each sample (either sawdust or rice husks) was placed in an individual bottle and water added to give moisture content of about $85 \%$. The bottles were autoclaved at $121^{\circ} \mathrm{C}$ for $20 \mathrm{~min}$ and were inoculated with $5 \%(\mathrm{w} / \mathrm{w})$ spawns of Ganoderma carnosum, Piptoporus betulius, Pleurotus ostreatus and Pleurotus eryinge [14] in triplicates. Gypsum and limestone were used to guarantee optimum $\mathrm{pH}$ favoring mushroom growth. The bottles were incubated in an incubator at $25^{\circ} \mathrm{C}$ until full colonization of substrate. Subsequently, the bottles were incubated at $16^{\circ} \mathrm{C}$ under light for about 10 h/day with a relative humidity of $95 \%$ for 2 weeks [16].

\section{Isolation of Intracellular and Extracellular Polysaccharides}

Basidiomycete biomass was separated from the fermentation broth by suction in a Buchner funnel as mentioned previously [17]. Four volumes of $95 \%(\mathrm{v} / \mathrm{v})$ 
ethanol were added to the filtrated to precipitate the EPS. The polysaccharides were recovered by centrifugation ( $30 \mathrm{~min}, 10000 \mathrm{rpm}$ ) and the precipitate was suspended in $5 \mathrm{ml}$ of $50 \mathrm{mM}$ phosphate buffer $\mathrm{pH}$ 6.5 containing $1 \mathrm{mM}$ benzamidine. The mycelial biomass suspension was incubated at $100^{\circ} \mathrm{C}$ for $2.5 \mathrm{~h}$ to release IPS. The mixture was filtered by suction and the filtrate containing polysaccharides were recovered the same way as the EPS.

As far as fruiting bodies of mushrooms are concerned, they were ground in a grinder and suspended in 3 volumes of distilled water which was incubated at $100^{\circ} \mathrm{C}$ for $3 \mathrm{~h}$. The suspension was centrifuged at $10.000 \mathrm{rpm}$ for $15 \mathrm{~min}$ at $4^{\circ} \mathrm{C}$ and the supernatant containing the polysaccharides was recovered and kept at $-20^{\circ} \mathrm{C}$.

\section{Protein and Polysaccharide Assays}

Protein quantification was carried out by Comassie blue dye binding method whereas polysaccharides were quantified by phenol/sulphuric acid method using the polygalacturonic acid as a standard and respectively $[18,19]$.

\section{Purification of Polysaccharides by Gel Filtration Chromatography}

EPS from $\mathrm{Ga}$ (1) and Po (1) were purified by gel filtration chromatography on Sephacryl S-300-HR column $(1 \times 100 \mathrm{~cm})$ which was eluted with $50 \mathrm{mM}$ phosphate buffer $\mathrm{pH} 7.0$ at a flow rate of $30 \mathrm{~mL} / \mathrm{h}$. Column factions were analyzed for polysaccharide $\left(A_{200}\right)$, phenol sulphuric acid method, protein $\left(A_{280}\right)$ and Comassie blue dye binding method.

\section{HPLC Analysis of Polysaccharides}

HPLC analysis was carried out by using Shodex column with $0.01 \%(\mathrm{w} / \mathrm{v})$ sodium azide as the solvent at a flow rate of $1 \mathrm{~mL} / \mathrm{min}$ and at $80^{\circ} \mathrm{C}$. IPS and EPS extracted as described above, were injected $(20 \mu \mathrm{L})$ and peak analysis was carried by UV and RI detectors.

\section{Determination of Superoxide Anions Scavenging Ability}

Superoxide anions were determined in mushroom extracts by the spectrophotometric measurement of the reduction of nitro blue tetrazolium (NTB), according to the method described by [20] with some modifications. Each sample $(25 \mu \mathrm{L})$ was mixed with $80 \mu \mathrm{M}$ phenazine methosulfate (PMS, $25 \mu \mathrm{L}$ ), $625 \mu \mathrm{M}$ dihydronico- tinamide adenine dinucleotide $(\mathrm{NADH}, 25 \mu \mathrm{L})$ and 200 $\mu \mathrm{M}$ nitro blue tetrazolium (NBT, $25 \mu \mathrm{L}$ ) prepared in 100 $\mathrm{mM}$ sodium phosphate buffer $\mathrm{pH}$ 7.4. After $5 \mathrm{~min}$ at room temperature the absorbance was measured at $550 \mathrm{~nm}$ (microplate reader Bio-Rad 680). All absorbance measurements were carried out in triplicate. Ascorbic acid and BHT were used as positive controls and the scavenging capability to superoxide radicals was calculated following the equation: Scavenging Ability $(\%)=\left[\left(\mathrm{A}_{\text {control }}-\mathrm{A}_{\text {sample }}\right) / \mathrm{A}_{\text {control }}\right]$ * $100 \%$, where $A_{\text {control }}$ is the absorbance of the negative control and $A_{\text {sample }}$ is the absorbance of the tested samples or standard at $550 \mathrm{~nm}$.

\section{FTIR Analysis of Polysaccharides}

Infrared spectra were recorded in a Bruker Tensor 27 FTIR spectrometer at $2 \mathrm{~cm}$ resolution. FTIR analysis of IPS from Ganoderma carnosum (s) and Pleurotus eryngii (s) as well as EPS from Ganoderma apllanatum (1) and Pleurotus ostreatus (1) was carried out in a Bruker Vertex 70 in $\mathrm{KBr}$ pellets in the range of $500-4000 \mathrm{~cm}^{-1}$.

\section{Effect of Polysaccharides on Growth of Human Carcinoma Cell Lines In Vitro}

Colorimetric assay based on 3-(4,5 dimethylthiazol-2-yl)-2,5-diphenyltetrazolium bromide (MTT) method was used to analyze the growth of human carcinoma HeLa, A549, A431 and OE21 cell lines in 96-well microtiter plates containing a suitable medium supplemented with $10 \%$ fetal bovine serum and gentamycin. For cell lines A431, A549 and HeLa cells were grown in Dulbecco's Modified Eagle's Medium (DMEM) containing gentamycin and 10\% fetal bovine serum (FBS) whereas cell line OE21 was grown in RPMI (Roswell Park Memorial Institute medium) medium, supplemented with FBS, penicillin and streptomycin.

Suitable concentrations of polysaccharides (i.e undiluted, 1:2, 1:10 and 1:50 dilutions) were added to each well containing $5.5 \times 10^{4}$ cells per well and the cultures were incubated in $\mathrm{CO}_{2}$ incubator with $5 \% \mathrm{CO}_{2}$ at $37{ }^{\circ} \mathrm{C}$ for $48 \mathrm{~h}$. The initial concentrations of these IPS and EPS from several mushroom strains are mentioned in Table 1. Cellular viability was quantified by the addition of $20 \mu \mathrm{l} \mathrm{MTT}(5 \mathrm{mg} / \mathrm{ml})$ to each microtiter wells and after $4 \mathrm{~h}$ incubation, the supernatant was removed and $200 \mu \mathrm{l}$ DMSO was added to each well to solubilize the precipitate. The viable cells of human carcinoma cell line was quantified by measuring 
Table 1: Assay of Intracellular and Extracellular Polysaccharides, Sugar and Protein (mg L ${ }^{-1}$ ) of Biomass, Culture Supernatants and Fruiting Bodies Produced in the Present Work

\begin{tabular}{|c|c|c|c|c|c|c|}
\hline \multirow{2}{*}{$\begin{array}{l}\text { Mushroom } \\
\text { strains }\end{array}$} & \multicolumn{3}{|c|}{ IPS } & \multicolumn{3}{|c|}{ EPS } \\
\hline & $\begin{array}{l}\text { Polysaccharide } \\
\qquad\left(\mathrm{mg} \mathrm{L}^{-1}\right)\end{array}$ & $\begin{array}{l}\text { Sugar } \\
\left(\mathrm{mg} \mathrm{L}^{-1}\right)\end{array}$ & $\begin{array}{l}\text { Protein } \\
\left(\mathrm{mg} \mathrm{L}^{1}\right)\end{array}$ & $\begin{array}{l}\text { Polysaccharide } \\
\quad\left(\mathrm{mg} \mathrm{L}^{-1}\right)\end{array}$ & $\begin{array}{l}\text { Sugar } \\
\left(\mathrm{mg} \mathrm{L}^{-1}\right)\end{array}$ & $\begin{array}{l}\text { Protein } \\
\left(\mathrm{mg} \mathrm{L}^{-1}\right)\end{array}$ \\
\hline $\mathrm{Gc}(\mathrm{s})^{*}$ & $3.25 \pm 0.21$ & 1.15 & 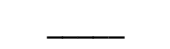 & $0.03 \pm 0.002$ & 0.08 & $\underline{ }$ \\
\hline $\mathrm{Pb}(\mathrm{r})^{*}$ & $6.71 \pm 0.53$ & 2.29 & 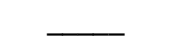 & $0.31 \pm 0.021$ & 0.18 & 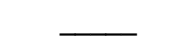 \\
\hline $\mathrm{Gc}(r)^{*}$ & $1.45 \pm 0.11$ & 0.55 & 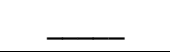 & $0.32 \pm 0.029$ & 0.18 & $\underline{-}$ \\
\hline $\mathrm{Pb}(1)$ & $8.33 \pm 0.63$ & 3.13 & $14.15 \pm 1.25$ & $36.38 \pm 3.55$ & 12.70 & $70.71 \pm 9.25$ \\
\hline Gc (1) & $12.94 \pm 0.91$ & 4.66 & $12.00 \pm 1.01$ & $45.54 \pm 4.91$ & 15.80 & $67.86 \pm 6.27$ \\
\hline II (1) & $2.06 \pm 0.27$ & 0.77 & $9.02 \pm 0.79$ & $1.83 \pm 0.190$ & 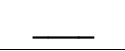 & $95.90 \pm 9.01$ \\
\hline $\mathrm{Pe}(2)$ & $3.68 \pm 0.33$ & 4.59 & $11.90 \pm 1.51$ & $3.68 \pm 0.35$ & 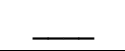 & $39.09 \pm 4.25$ \\
\hline $\mathrm{Ga}(1)$ & $20.78 \pm 2.09$ & 7.25 & $9.95 \pm 0.93$ & $11.35 \pm 1.24$ & 4.50 & $26.82 \pm 2.54$ \\
\hline $\mathrm{Ga}(2)$ & $12.50 \pm 1.01$ & 4.53 & $4.79 \pm 0.47$ & 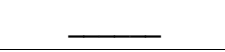 & 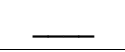 & $37.87 \pm 4.20$ \\
\hline $\mathrm{Ba}(2)$ & $42.20 \pm 3.25$ & 14.35 & $4.42 \pm 0.39$ & $42.54 \pm 4.53$ & 14.70 & $36.33 \pm 4.41$ \\
\hline $\mathrm{Pe}(\mathrm{s})^{*}$ & $0.46 \pm 0.03$ & 0.53 & $24.0 \pm 2.55$ & - & - & $19.80 \pm 2.45$ \\
\hline Po $(s)^{*}$ & $0.76 \pm 0.21$ & 0.63 & $18.81 \pm 1.75$ & 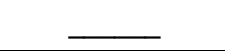 & $\underline{-}$ & $58.71 \pm 5.90$ \\
\hline Le (1) & $6.16 \pm 0.21$ & 2.42 & $35.90 \pm 3.09$ & $50.81 \pm 5.52$ & 17.50 & $26.08 \pm 3.23$ \\
\hline
\end{tabular}

Ba - Bjerkandera adjusta; EPS- Extracellular polysaccharides; Ga - Ganoderma apllanatum; Gc - Ganoderma carnosum; II - Irpex lacteus; IPS - Intracellular polysaccharides; Le - Lentinula edodes; Pb - Piptoporus betulius; Pe - Pleurotus eryinge; Po - Pleurotus ostreatus; $\mathrm{r}$ - medium with rice husks; $\mathrm{s}$ - medium with straw; 1 - Culture medium 1 with boiled wheat water, glucose and yeast extract; 2 - Culture medium 2 with boiled wheat water, glucose and tomato pomace; ${ }^{*}$ - mg/kg fruiting bodies; --- Not detected.

the optical density in a microtiter plate reader at 560 $\mathrm{nm}$. These results were expressed as the inhibition ratio $(\phi)$ of human carcinoma cell line growth as follows: $\phi=[A-B] / A \times 100 \%$

$A$ and $B$ are the average number of viable tumor cells of the control (i.e either culture medium or starch) and test samples, respectively. Normal cells were also used to investigate the effect of highest concentration of polysaccharides on cell growth in vitro. All assays were carried out in triplicate.

\section{Statistical Analysis}

SigmaPlot 12.0 (2011-2012 Systat Software inc.) was used to draw graphs in this research work. Experimental results are means of three parallel measurements and the results are presented as mean values \pm standard deviation (SD). Correlation and regression analyses were performed with the Excel software 2013 package (Academic License, Microsoft of Portugal). Correlations were considered statistically significant at $p<0.05$ according to Tukey HSD and Scheffé test.

\section{RESULTS}

Mushroom strains were grown in culture media 1 and 2 as well as by solid state fermentation and the levels of carbohydrates, polysaccharides and proteins were determined as shown in Table 1. IPS levels were in the range of $0.46 \pm 0.03$ to $42.20 \pm 3.25 \mathrm{mg} \mathrm{L}-1$ of culture medium for $\mathrm{Pe}(\mathrm{s})$ and $\mathrm{Ba}(2)$, respectively. As far as EPS are concerned, the data presented in Table 1 has revealed levels in the range of $0.03 \pm 0.002$ to $50.81 \pm 5.52 \mathrm{mg} \mathrm{L}-1$ of culture medium for $\mathrm{Gc}(\mathrm{s})$ and Le (1), respectively. As far as SO scavenging activity of IPS is concerned, ascorbic acid was used as positive control exhibiting activity of $85.89 \pm 9.20 \%$ (Table 2). Mushroom IPS have revealed scavenging activity in the range of $22.08 \pm 3.06$ to $81.13 \pm 9.07 \%$ for Po (s) and $\mathrm{Pe}$ (2), respectively (Table 2). On the other hand, IPS previously concentrated by precipitation with ethanol 
Table 2: SO Scavenging Activity (\%) of IPS from Mushroom Strains by Using Several Dilution Factors. Ascorbic Acid (AA) $\left(200 \mu \mathrm{g} \mathrm{mL}^{-1}\right)$ was Used as a Positive Control

\begin{tabular}{|c|c|c|c|c|}
\hline $\begin{array}{l}\text { Dilution } \\
\text { Factor }\end{array}$ & $\begin{array}{c}\text { so Scavenging (\%) } \\
\text { II (1) }\end{array}$ & $\begin{array}{c}\text { So Scavenging (\%) } \\
\text { Po (1) }\end{array}$ & $\begin{array}{c}\text { So Scavenging (\%) } \\
\operatorname{Pe}(2)\end{array}$ & $\begin{array}{c}\text { So Scavenging (\%) } \\
\text { Po (s) }\end{array}$ \\
\hline Neat & $56.83 \pm 3.06$ & $50.07 \pm 4.01$ & $81.13 \pm 9.07$ & $22.08 \pm 3.06$ \\
\hline $1: 2$ & $39.25 \pm 2.01$ & $36.54 \pm 4.07$ & $68.78 \pm 7.06$ & $17.7 \pm 1.27$ \\
\hline $1: 4$ & $15.39 \pm 1.02$ & $31.73 \pm 4.02$ & $39.26 \pm 4.01$ & $N D^{*}$ \\
\hline $1: 16$ & $4.28 \pm 0.39$ & $8.58 \pm 0.92$ & $11.42 \pm 1.07$ & $10.65 \pm 1.01$ \\
\hline \multirow[t]{2}{*}{$1: 64$} & $N D^{*}$ & $N D^{*}$ & $11.68 \pm 1.06$ & $9.17 \pm 0.95$ \\
\hline & $\operatorname{Pe}(s)$ & $\mathrm{Ga}(1)$ & $\mathrm{Ga}(2)$ & II (2) \\
\hline Neat & $63.42 \pm 4.05$ & $67.22 \pm 7.02$ & $76.57 \pm 6.01$ & $50.50 \pm 5.09$ \\
\hline $1: 2$ & $51.30 \pm 3.02$ & $45.71 \pm 5.06$ & $50.66 \pm 4.03$ & $27.72 \pm 3.07$ \\
\hline $1: 4$ & $25.37 \pm 2.14$ & $23.87 \pm 3.05$ & $20.46 \pm 3.12$ & $14.85 \pm 2.06$ \\
\hline 1:16 & $1.13 \pm 0.13$ & $4.79 \pm 0.52$ & $4.62 \pm 0.55$ & $5.06 \pm 0.74$ \\
\hline \multirow[t]{2}{*}{$1: 64$} & $4.64 \pm 0.31$ & $N^{*}$ & $N D^{*}$ & $1.65 \pm 0.16$ \\
\hline & $\mathrm{Pb}(\mathrm{s})$ & $\mathrm{Pb}(\mathrm{r})$ & Gc (r) & $\mathrm{Ba}(2)$ \\
\hline Neat & $70.78 \pm 6.03$ & $68.83 \pm 7.04$ & $73.43 \pm 6.04$ & $76.57 \pm 8.01$ \\
\hline $1: 2$ & $54.70 \pm 4.06$ & $59.21 \pm 6.03$ & $55.39 \pm 5.09$ & $63.53 \pm 6.06$ \\
\hline $1: 4$ & $24.80 \pm 3.08$ & $27.23 \pm 3.17$ & $30.13 \pm 4.13$ & $21.78 \pm 2.07$ \\
\hline $1: 16$ & $12.23 \pm 1.02$ & $48.78 \pm 4.01$ & $10.08 \pm 1.03$ & $6.60 \pm 0.71$ \\
\hline $1: 64$ & $4.19 \pm 0.37$ & $16.45 \pm 2.26$ & $5.45 \pm 0.33$ & $3.47 \pm 0.49$ \\
\hline
\end{tabular}

Ba - Bjerkandera adjusta; Ga - Ganoderma apllanatum; Gc - Ganoderma carnosum; II - Irpex lacteus; Pb - Piptoporus betulius; Pe - Pleurotus eryinges; Po Pleurotus ostreatus; $r$ - medium with rice husks; s- medium with straw; 1 - Culture medium 1 with boiled wheat water, glucose and yeast extract; 2 - Culture medium 2 with boiled wheat water, glucose and tomato pomace. ${ }^{*}$ Not detected.

Table 3: SO Scavenging (\%) of IPS from Mushroom Strains which were Previously Precipitated with Ethanol. Several Dilution Factors were Used and Ascorbic Acid $\left(200 \mu \mathrm{g} \mathrm{m}^{-1}\right)$ was Used as a Positive Control

\begin{tabular}{|c|c|c|c|c|}
\hline Dilution Factor & $\mathrm{Ba}(2)$ & II (1) & II (2) & $\mathrm{Pe}(2)$ \\
\hline Neat & $61.96 \pm 7.08$ & $48.55 \pm 5.411$ & $80.86 \pm 9.01$ & $48.24 \pm 5.09$ \\
\hline $1: 2$ & $42.05 \pm 5.18$ & $37.48 \pm 4.04$ & $39.22 \pm 4.13$ & $37.32 \pm 4.02$ \\
\hline $1: 4$ & $24.52 \pm 3.07$ & $28.81 \pm 3.03$ & $38.45 \pm 3.00$ & $18.60 \pm 1.61$ \\
\hline $1: 16$ & $23.93 \pm 2.11$ & $12.33 \pm 1.04$ & $23.71 \pm 2.02$ & $8.97 \pm 0.92$ \\
\hline $1: 64$ & $3.42 \pm 0.29$ & $11.82 \pm 0.21$ & $8.71 \pm 0.77$ & $1.43 \pm 0.19$ \\
\hline Dilution Factor & Ga (1) & $\mathrm{Ga}(2)$ & Po (1) & \\
\hline Neat & $80.99 \pm 7.02$ & $65.92 \pm 5.05$ & $50.07 \pm 6.00$ & \\
\hline $1: 2$ & $34.91 \pm 4.13$ & $50.72 \pm 5.05$ & $36.54 \pm 3.07$ & \\
\hline $1: 4$ & $32.89 \pm 3.02$ & $30.24 \pm 3.11$ & $31.73 \pm 3.95$ & \\
\hline $1: 16$ & $22.50 \pm 2.05$ & $20.69 \pm 2.28$ & $8.58 \pm 0.72$ & \\
\hline $1: 64$ & $8.79 \pm 9.39$ & $6.33 \pm 0.60$ & $N D^{*}$ & \\
\hline
\end{tabular}

Ba - Bjerkandera adjusta; Ga - Ganoderma apllanatum; II - Irpex lacteus; Pe - Pleurotus eryinge; Po - Pleurotus ostreatus; 1 - Culture medium 1 with boiled wheat water, glucose and yeast extract; 2 - Culture medium 2 with boiled wheat water, glucose and tomato pomace. ${ }^{*}$ Not detected.

exhibited levels in the range of $48.24 \pm 5.09$ to 80.99 $\pm 7.02 \%$ for Pe (2) and $\mathrm{Ga}(1)$, respectively (Table 3 ).

Fractions containing IPS and EPS from Lentinula edodes were characterized by HPLC which revealed
UV and RI peaks with retention times in the range of 6 13 min (Figure 1).

EPS from Ganoderma apllanatum (1) and Pleurotus ostreatus (1) were isolated by precipitation with alcohol 


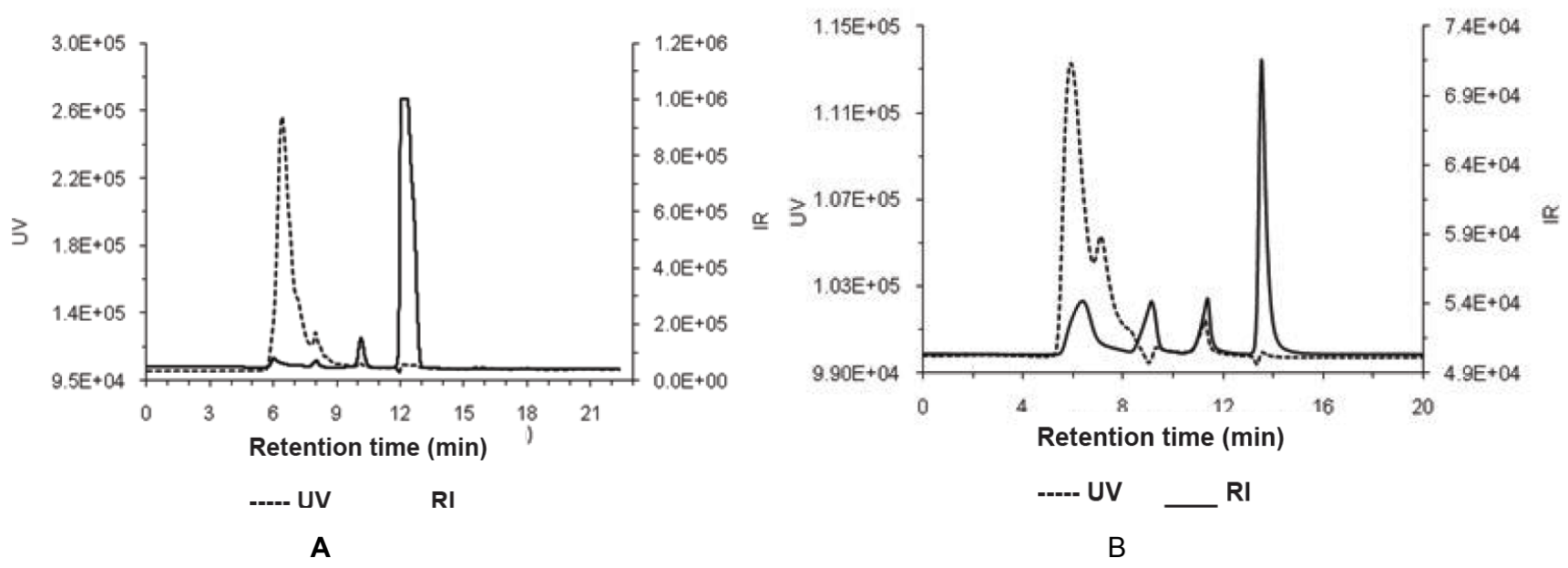

Figure 1: A. HPLC analysis of IPS from Lentinula edodes. B. HPLC analysis of EPS from Lentinula edodes.

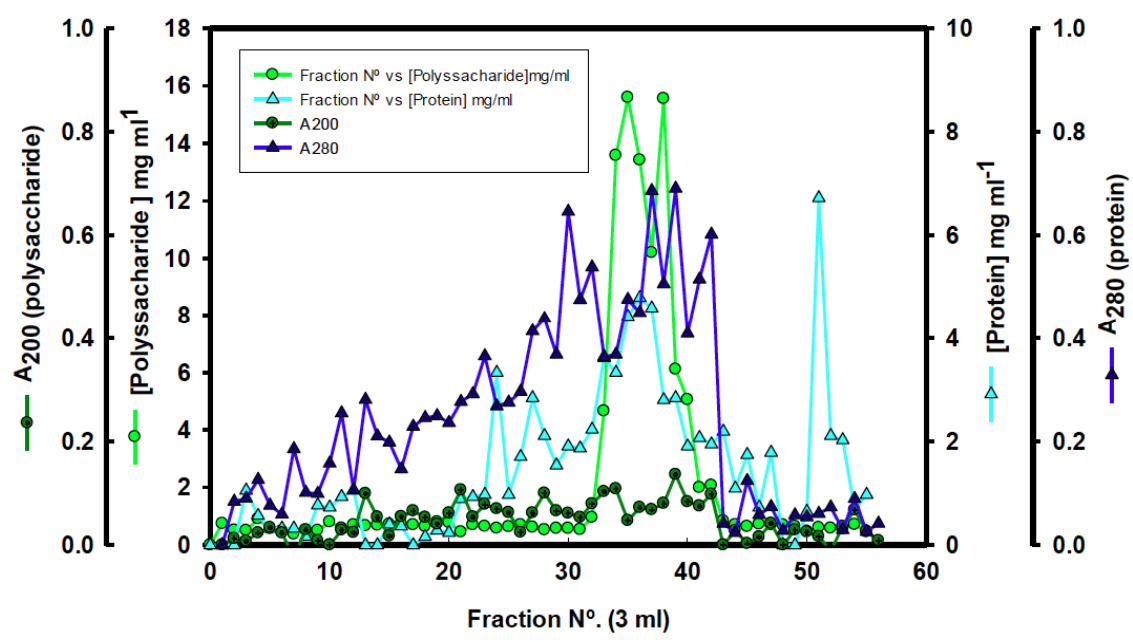

A

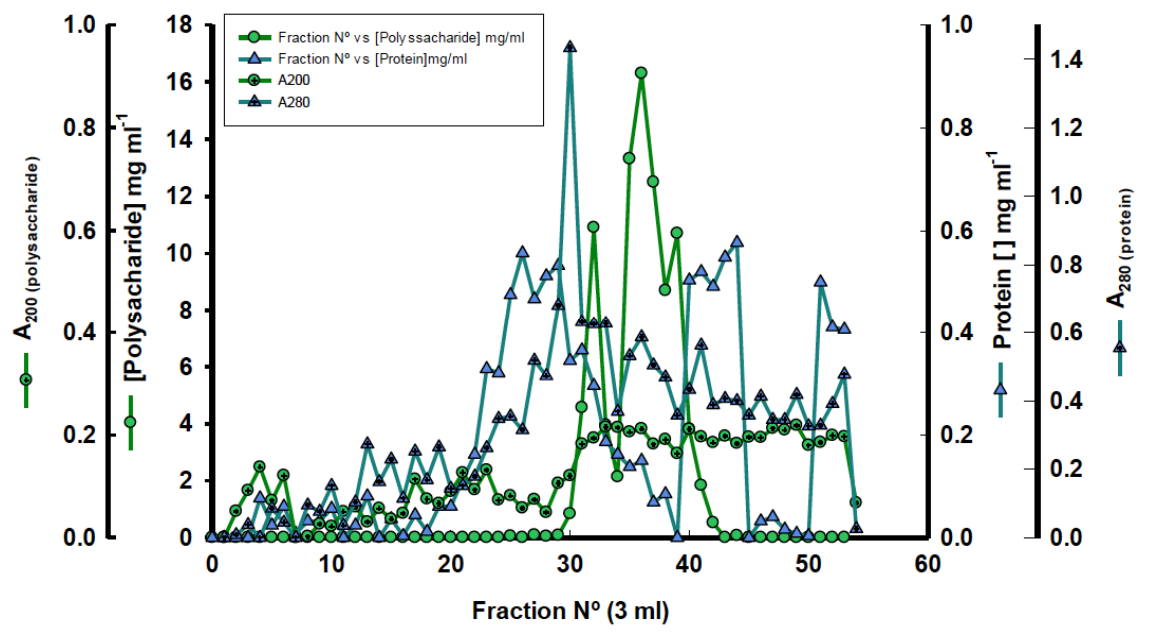

B

Figure 2: A. Chromatographic behavior of EPS from Ganoderma applanatum on gel filtration chromatography packed with Sephacryl S-300 HR and column fractions were monitored for polysaccharide and protein content by the phenol - sulphuric acid and coomassie blue methods as well as for protein $\left(A_{280}\right)$ and polysaccharide $\left(A_{200}\right)$ concentrations. B. Chromatographic behavior of EPS from Pleurotus ostreatus on Sephacryl S-300 HR column and column fractions were monitored for polysaccharide and protein content by the phenol - sulphuric acid and coomassie blue methods as well as for protein $\left(\mathrm{A}_{280}\right)$ and polysaccharide $\left(\mathrm{A}_{200}\right)$ concentrations. 


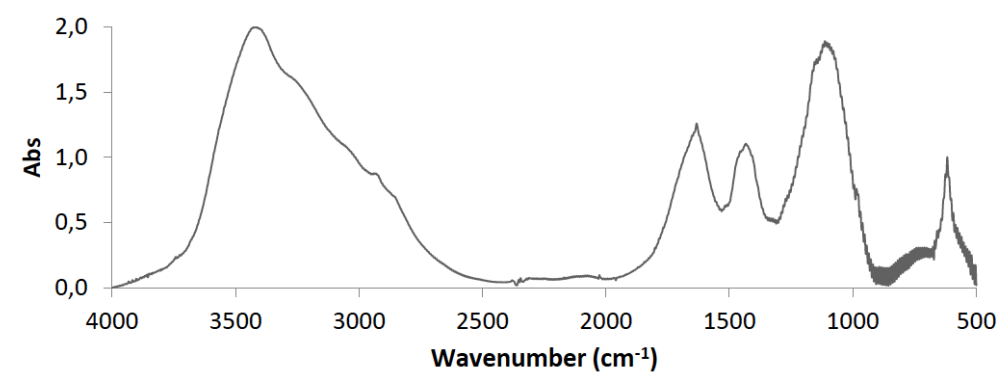

A

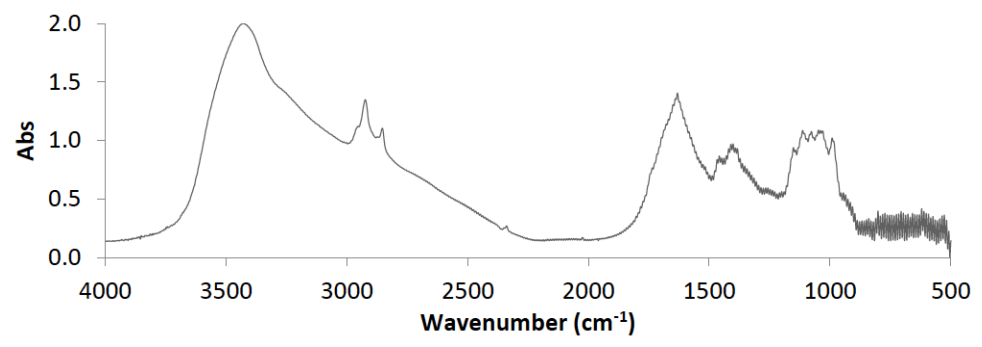

B

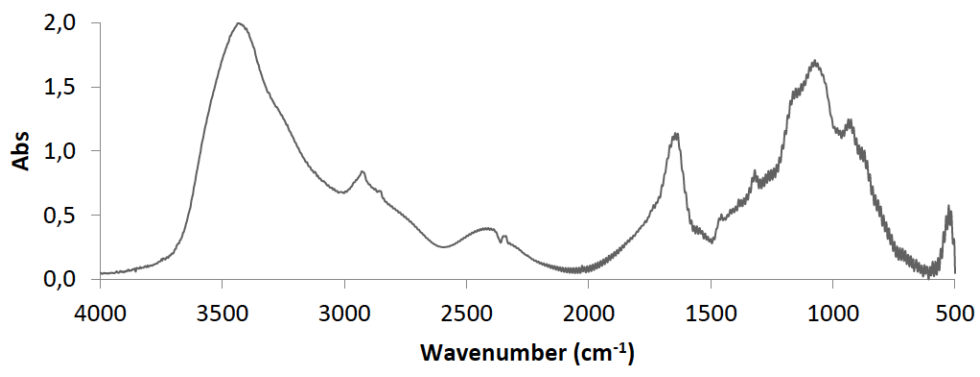

C

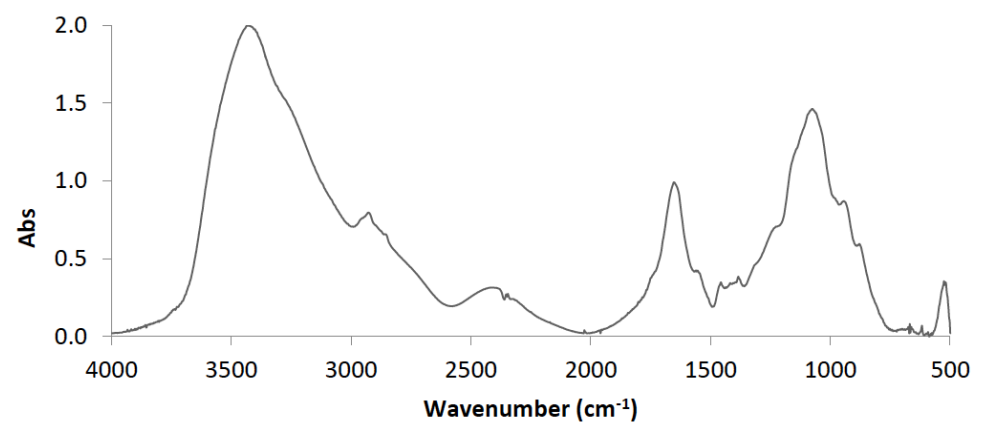

D

Figure 3: A. FTIR spectrum of IPS from Ganoderma carnosum grown on straw culture medium. B. FTIR spectrum of IPS from Pleurotus eryngi grown on straw culture medium. C. FTIR spectrum of EPS from Ganoderma applanatum grown in culture medium 1. D. FTIR spectrum of EPS from Pleurotus ostreatus grown in culture medium 1.

and were purified by gel filtration chromatography on Sephacryl S-300-HR column (Figure 2). Column fractions were monitored for polysaccharide and protein content by the phenol - sulphuric acid and coomassie blue methods as well as for protein $\left(A_{280}\right)$ and polysaccharide $\left(A_{200}\right)$ readings. The data presented in Figure 2 has revealed that the highest concentration of EPS were found in column fractions in the range of 30 to 40 in both chromatographic runs and therefore these were selected for investigation for their potential growth inhibition of human carcinoma cell lines in vitro.

Fourier Transform Infrared (FTIR) spectroscopy was used to investigate the structure of such polysaccharides (i.e IPS extracted from $\mathrm{Gc}(\mathrm{s})$ and $\mathrm{Pe}$ (s), and EPS from Po (1) and Ga (1)) which revealed some characteristic absorption bands of these biological macromolecules at appropriate frequencies (Figure 3). 


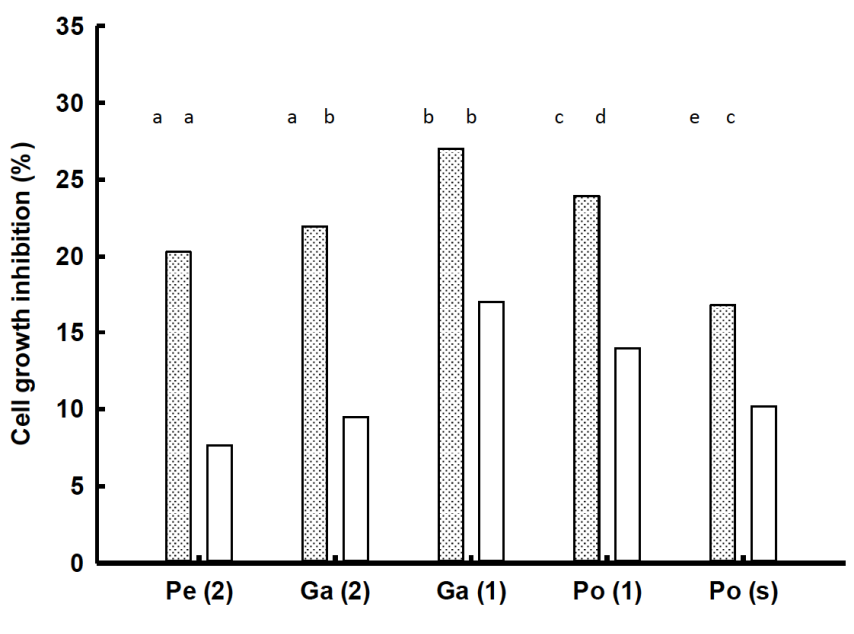

A
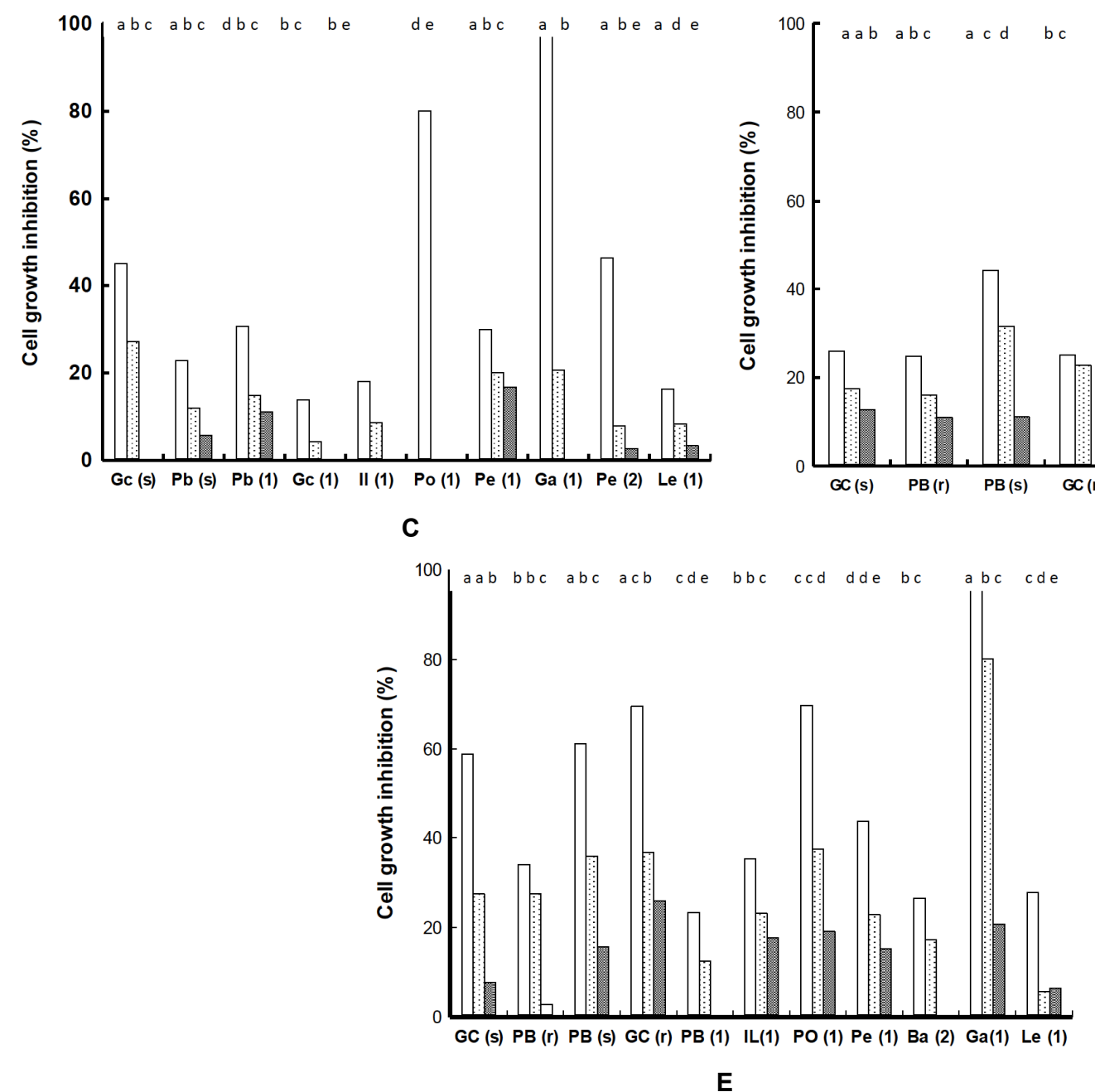
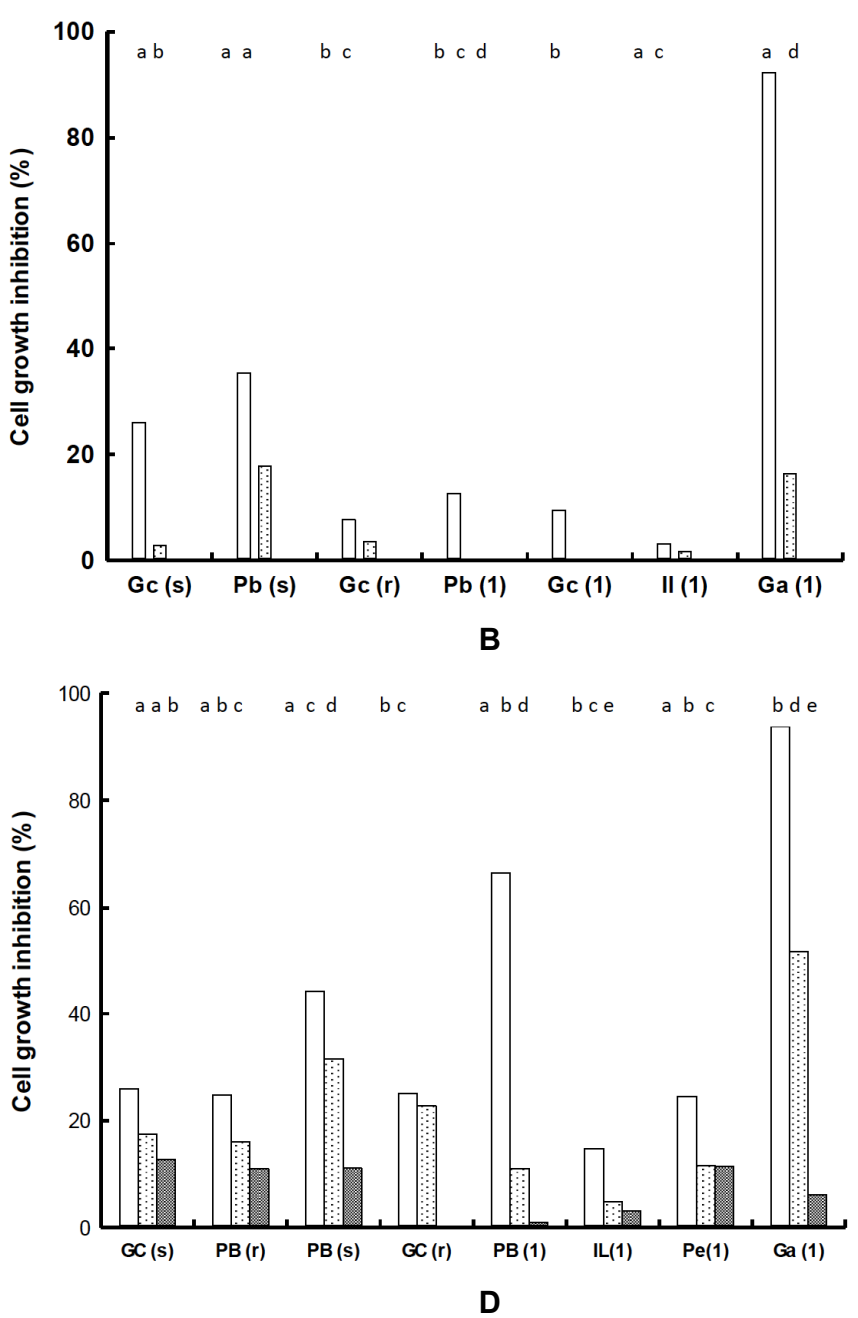

Figure 4: A. Cell growth inhibition (\%) by addition of IPS at $1000 \mu \mathrm{g} / \mathrm{mL}$ and $200 \mu \mathrm{g} / \mathrm{mL}$ to the HeLa cell line (Dotted and open columns, respectively); mean of triplicate values and error bars are represented. Values with different letters were significantly different $(p<0.05)$ according to Tukey HSD and Scheffé tests. B. Cell growth inhibition $(\%)$ by addition of EPS to HeLa cell line; undiluted, $1: 2$ and 1:10 dilution of EPS samples. (open, dotted and dark dotted columns, respectively); Gc (s):37.5, 18.75 and $3.75 \mu \mathrm{g} / \mathrm{ml} ; \mathrm{Pb}(\mathrm{s}): 90.8,45.4$ and $9.08 \mu \mathrm{g} / \mathrm{ml} ; \mathrm{Gc}(\mathrm{r}): 326,163$ and $32.6 \mu \mathrm{g} / \mathrm{ml} ; \mathrm{Pb}(1): 36.38,18.19,3.63 \mathrm{mg} / \mathrm{ml} ; \mathrm{Gc}(1): 45.54$, 22.77 and $4.55 \mathrm{mg} / \mathrm{ml}$; II (1): 1.83, 0.915 and $0.183 \mathrm{mg} / \mathrm{ml} ; \mathrm{Ga}(1): 11.35,5.675$ and $1.13 \mathrm{mg} / \mathrm{ml}$, respectively; mean of triplicate values and error bars are represented. Values with different letters were significantly different $(p<0.05)$ according to Tukey HSD and Scheffé tests. C. Cell growth inhibition (\%) by addition of EPS to A549 cell line; Gc (s), Po (1), Pe (2), Pe (1) and Pb (1) inhibitions were obtained from left to right with undiluted, $1: 2$ and $1: 10$ dilutions; Gc (s):37.5, 18.75 and $3.75 \mu \mathrm{g} / \mathrm{ml}$; Po (1) : 14.29, 7.15 and $1.42 \mathrm{mg} / \mathrm{ml}$; Pe (2) : 3.68, 1.84 and $0.36 \mathrm{mg} / \mathrm{ml} ; \mathrm{Pe}(1): 3.87,1.93$ and $0.38 \mathrm{mg} / \mathrm{ml} ; \mathrm{Pb}$ (1): $36.38,18.19$ and 3.63 
$\mathrm{mg} / \mathrm{ml}$, respectively; the remaining EPS from $\mathrm{Pb}(\mathrm{s})$, II (1), Ga (1) and Le (1) were used from left to right with a 1:2, 1:10 and 1:50 PBS dilutions (open, dotted and dark dotted columns, respectively); Pb (s): 45.4, 9.08 and $1.81 \mu \mathrm{g} / \mathrm{ml}$; II (1): $0.915,0.183$ and $0.036 \mathrm{mg} / \mathrm{ml}$; Ga (1): $5.67,1.13$ and $0.26 \mathrm{mg} / \mathrm{ml}$; Le (1): $25.40,5.08$ and $1.01 \mathrm{mg} / \mathrm{ml}$, respectively; mean of triplicate values and error are represented samples. Mean of triplicate values and error bars are represented. Values with different letters were significantly different $(p<0.05)$ according to Tukey HSD and Scheffé tests. D. Cell growth inhibition (\%) by addition of EPS to A431; From left to right: undiluted samples, $1: 2$ and 1:10 dilutions are represented; Gc (s): $37.5,18.75 \mathrm{and} 3.75 \mu \mathrm{g} / \mathrm{ml}$; $\mathrm{Pb}$ (r): 313, 156 and $31.3 \mu \mathrm{g} / \mathrm{ml} ; \mathrm{Pb}(\mathrm{s}): 90.8,45.4$ and $9.08 \mu \mathrm{g} / \mathrm{ml} ; \mathrm{Gc}(\mathrm{r}): 326,163$ and $32.6 \mu \mathrm{g} / \mathrm{ml} ; \mathrm{Pb}$ (1): 36.38, 18.19, $3.63 \mathrm{mg} / \mathrm{ml}$; II (1): $1.83,0.915$ and 0.183 ; Pe (1): $3.87,1.93$ and $0.38 \mathrm{mg} / \mathrm{ml} ; \mathrm{Ga}(1): 11.35,5.675$ and $1.13 \mathrm{mg} / \mathrm{ml}$, respectively; except for $\mathrm{Gc}(\mathrm{s}): 18.75,3.75$ and $0.75 \mu \mathrm{g} / \mathrm{ml}$, which is also from left to right to a 1:2, 1:10 and 1:50 PBS dilutions, respectively; Samples are represented as open, dotted and dark dotted columns, respectively. Mean of triplicate values and error bars are represented. Values with different letters were significantly different $(p<0.05)$ according to Tukey HSD and Scheffé tests.

The effect of polysaccharides from several mushroom strains was investigated on potential growth inhibition of human carcinoma cell lines by using different concentrations of polysaccharides (Figure 4). Therefore, IPS inhibited cell growth of HeLa cell line in the range of $16.8-27.01 \%$ in the following decreasing order of mushroom strains: $\mathrm{Ga}(1)>\mathrm{Ga}(2)>\mathrm{Po}(1)>$ $\mathrm{Pe}(2)>\mathrm{Po}$ (s). On the other hand, EPS inhibited cell growth of HeLa, A549, A431 and OE21 in the ranges of $3.08-92.2 \%, 13.8-97.4 \%, 14.7-93.8 \%$ and $25-$ $94 \%$ in the following decreasing order of mushroom strains, respectively : $\mathrm{Ga}(1)>\mathrm{Pb}$ (s) $>\mathrm{Gc}(\mathrm{s})>\mathrm{Pb}(1)$ $>\mathrm{Gc}(1)>\mathrm{Gc}(\mathrm{r})>$ II (1); $\mathrm{Ga}(1)>\mathrm{Po}(1)>\mathrm{Pe}(2)>\mathrm{Gc}$ (s) $>\mathrm{Pb}(1)>\mathrm{Pe} \mathrm{(1)}>\mathrm{Pb}$ (s) > II (1) > Le (1) > Gc (1); $\mathrm{Ga}(1)>\mathrm{Pb}(1)>\mathrm{Pb}(\mathrm{s})>\mathrm{Pe}(1)>\mathrm{Gc}(\mathrm{r})>\mathrm{Pb}(\mathrm{r})>\mathrm{II}$ (1) and $\mathrm{Ga}(1)>\mathrm{Po}_{\text {(1) }}>\mathrm{Gc}(\mathrm{r})>\mathrm{Gc}(\mathrm{s})>\mathrm{Pb}$ (s) $>\mathrm{Pe}$ (1) $>\mathrm{Ba}$ (2)> II (1) > Pb (r) > Pb (1) > Le (1), respectively (Figure 4). Normal cells were also used to investigate the effect of highest concentration of polysaccharides on cell growth in vitro which revealed no growth inhibition of normal cells (data not shown).

\section{Effect of Purified Fractions of EPS on Proliferation of Human Carcinoma Cell Lines}

EPS were purified by gel filtration chromatography and the effect of chromatographic fractions was investigated on cell growth of two human carcinoma cell lines A549 and OE21 as shown in Figure 5. As far as Po (1) samples are concerned, column fractions 31 to 42 were selected whereas $\mathrm{Ga}$ (1) column samples fractions 33 to 42 were used due to high levels of polysaccharide exhibited in data represented in Figures 5A and 5B, respectively. Moreover, these EPS samples were also concentrated by precipitation with $95 \%$ alcohol as described in Materials and Methods and these concentrated samples were represented as Po (1) pp or $\mathrm{Ga}$ (1) pp (Figure 5). Similarly, normal cells were also used to investigate the effect of

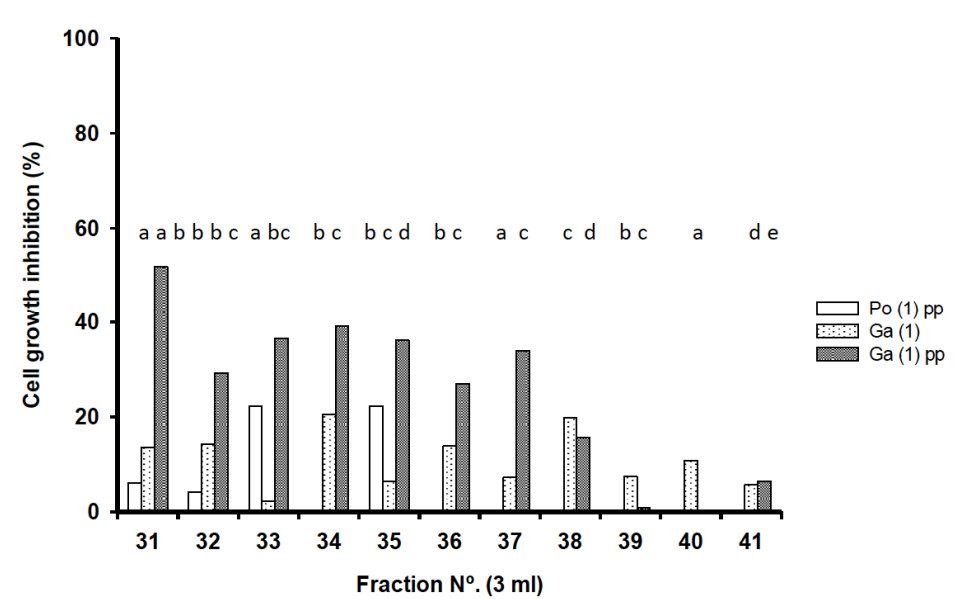

A

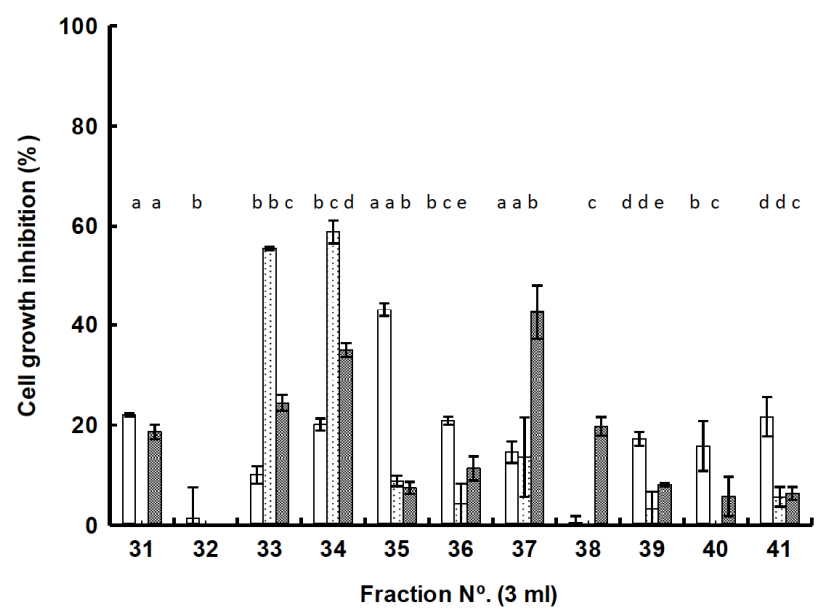

B

Figure 5: A. Effect of column fractions from gel filtration chromatography of EPS from Ga (1) and Po (1) on growth inhibition of cell line A549; fractions described as pp have been purified by alcohol precipitation after gel filtration chromatography. Samples are represented as open, dotted and dark dotted columns, respectively. Mean of triplicate values and error bars are represented. Values with different letters were significantly different $(p<0.05)$ according to Tukey HSD and Scheffé tests. B. Effect of column fractions from gel filtration chromatography of EPS from Ga (1) and Po (1) on growth inhibition of cell line OE21; fractions described as pp have been purified by alcohol precipitation after gel filtration chromatography. The legends are the same as in Figure 5A. Samples are represented as open, dotted and dark dotted columns, respectively. Mean of triplicate values and error bars are represented. Values with different letters were significantly different $(p<0.05)$ according to Tukey HSD and Scheffé tests. 
chromatographic fractions containing purified polysaccharides on cell growth in vitro which revealed no growth inhibition of normal cells (data not shown).

\section{DISCUSSION}

Highest concentrations of IPS were obtained from $\mathrm{Ba}(2), \mathrm{Ga}(1), \mathrm{Gc}(1)$ and $\mathrm{Ga}(2)$ whereas high levels of EPS were found in Le (1), Gc (1), Ba (2) and $\mathrm{Pb}$ (1) (Table 1). Polysaccharide levels reported in the literature are highly variable because they are dependent on the nature of mushroom strain, growth substrate, culture conditions and either submerged or solid state fermentation. For instance, there is a report which described polysaccharide production in the range of 0.12 to $42.24 \mathrm{~g} \mathrm{~L}-1$ in submerged fermentation whereas there is another report mentioned polysaccharide production in the range of $4.5 \mathrm{mg} / \mathrm{g}$ and $1.05 \mathrm{mg} / \mathrm{g}$ of solid substrate in solid state fermentation $[21,22]$.

As far as SO radical scavenging activity is concerned, Table 2 has revealed highest activities for $\mathrm{Pe}(2), \mathrm{Ba}(2), \mathrm{Ga}(2), \mathrm{Gc}(\mathrm{r})$ and $\mathrm{Pb}(\mathrm{s})$ which exhibited SO radical scavenging activity in a concentrationdependent manner as reported previously [23]. In order to investigate the effect of time on SO scavenging activity of IPS extracts, absorbance measurements of reaction mixtures were carried out at 5 minute intervals for 30 minutes. It was found that $\mathrm{SO}$ radical scavenging activity did not alter significantly as a function of time for all IPS extracts (data not shown). Regarding IPS that were previously precipitated with ethanol, the highest levels of scavenging activity were observed in $\mathrm{Ga}$ (1), II (2), $\mathrm{Ga}(2)$ and $\mathrm{Ba}$ (2) which are not in agreement with Table 2. This discrepancy may be due to the fact that these are crude extracts and therefore there is precipitation of other secondary metabolites which affected SO radical scavenging activity.

Different retention times were obtained for intracellular and extracellular polysaccharides in HPLC as far as UV and RI peaks are concerned (Figure 1) which are similar to those reported in the literature $[17,24]$.

The chromatographic behavior of EPS from Ganoderma applanatum and Pleurotus ostreatus suggests the presence of at least two polysaccharide peaks as well as several protein peaks (Figure 2). The data presented in both chromatograms exhibited highest polysaccharide levels in column fractions 30 40 which were used to investigate their effect on cell growth of human carcinoma cell lines.
IPS from Ganoderma carnosum grown in straw culture medium (Figure $\mathbf{3 A}$ ) exhibited some characteristic absorption bands at appropriate frequencies. A strong band at $3420 \mathrm{~cm}^{-1}$ due to $-\mathrm{OH}$ stretching vibration is observed which can also be accompanied by the extension of the $-\mathrm{OH}$ group belonging to the $\mathrm{H} 2 \mathrm{O}$ molecule. A band at $2973 \mathrm{~cm}^{-1}$ is due to $\mathrm{C}-\mathrm{H}$ group vibration which suggests the presence of carbohydrate rings. The absorption band at $1632 \mathrm{~cm}^{-1}$ corresponds to vibration of the carbonyl group $(\mathrm{C}=\mathrm{O})$ of amide I whereas the band at $1435 \mathrm{~cm}^{-1}$ is due to $\mathrm{C}-\mathrm{OH}$ in plane bending. The stretching band at $1095 \mathrm{~cm}^{-1}$ in FTIR spectrum suggests apparently the presence of $\mathrm{C}-\mathrm{O}-\mathrm{C}$ bonds found in glucan molecules $[25,26]$. Absorption bands highly overlapped in the region of $1200-950 \mathrm{~cm}-1$ (mainly due to $\mathrm{C}-\mathrm{C}$ and $\mathrm{C}-\mathrm{O}$ stretching vibrations in pyranoid rings) suggested apparently the presence of polysaccharides as the major component $[25,26]$. FTIR spectrum of IPS from Pleurotus eryngii (Figure 3B) exhibited absorption bands at about the same frequencies as in Figure $\mathbf{3 A}$.

FTIR spectra of EPS from Ganoderma apllanatum and Pleurotus ostreatus revealed similar bands as well as an additional absorption band at $515 \mathrm{~cm}^{-1}$ and 526 $\mathrm{cm}^{-1}$ (Figure $3 \mathrm{C}$ and $\mathrm{D}$ ), respectively due to the presence of $\alpha$-glucans [25-28].

The effect of IPS and EPS from several mushroom strains was investigated on potential growth inhibition of different human carcinoma cell lines in vitro (Figure 4). Therefore, IPS inhibited cell growth of HeLa cell line in the range of $16.8-27.01 \%$ and the highest inhibition was observed for $\mathrm{Ga}$ (1) (Figure 4A). The data also revealed that cell growth inhibition is dependent on the amount of polysaccharide present since different dilutions were used in the present work. Moreover, cell growth inhibition was also dependent on the human carcinoma cell line used. On the other hand, EPS inhibited cell growth of HeLa , A549, A431 and OE21 in the ranges of $3.08-92.2 \%, 13.8-97.4 \%$, $14.7-93.8 \%$ and $25-94 \%$, respectively and the highest inhibition was obtained for EPS from $\mathrm{Ga}(1)$ in all cell lines (Figure 4B-D). The most surprising result in the present work was the most powerful inhibitory effect of EPS from $\mathrm{Ga}$ (1) on all human carcinoma cell lines (Figure 4). This EPS exhibited the highest cell growth inhibition of over $90 \%$ in all cell lines. The data presented in Figure $\mathbf{4}$ has revealed that cell growth inhibition is dependent on several factors such as the nature of mushroom strains and human carcinoma cell lines, IPS and EPS concentration and the composition of the growth medium used for mushroom strains. 
Therefore, some EPS from two mushroom strains ( $\mathrm{Ga}$ and $\mathrm{Po}$ ) were selected to carry out purification by gel filtration chromatography (Figure 2) in order to investigate their effect on cell growth of two human carcinoma cell lines A549 and OE21 as shown in Figure 5. Some purified column fractions exhibited a significant cell growth inhibition of both human carcinoma cell lines in the range of $20-55 \%$ and $10-$ $60 \%$ for A459 and OE21, respectively. These results are lower than those obtained by using crude EPS from both mushroom strains (Figure 4) which may be due to the dilution of column fractions as well as the removal of other secondary metabolites and polysaccharides involved in synergistic action on cell growth inhibition (Figure 5). As far as literature is concerned, there are only two reports in the literature about growth inhibition by purified polysaccharides from Pleurotus ostreatus on human carcinoma cell lines [12,13]. From the literature search, the authors did not find any reports about the effect of all IPS and EPS from these mushroom strains described in the present work as well as all human carcinoma cell lines used. Moreover, no published reports were found in the literature about all culture medium used for growth of these mushroom strains. However, there are several published works about the inhibitory effect of mushroom polysaccharides on growth of human carcinoma cell lines [29-31]. which are in general agreement with the data presented in this work. But it is difficult to compare these published data with the present work since different human cell lines, extraction procedures, mushroom strains, culture media for mushroom growth and different submerged or solid state fermentations were used.

Further work is required to carry out experimental planning of mushroom production of IPS and EPS extract preparations as a function of nature of solvents, $\mathrm{pH}$ of solvent, time and temperature of incubation of mushroom extract in order to obtain the highest yield of polysaccharides. Moreover, a detailed purification of the crude mushroom extract must be performed by using chromatographic techniques such as affinity, ionexchange and gel filtration chromatography. Subsequently, the purified polysaccharide preparations must be analyzed for their potential cell growth inhibition of human carcinoma cell lines in vitro. On the other hand, secondary metabolites and polysaccharides responsible for growth inhibition must be identified by analytical techniques such as FTIR, quantitative NMR, HPLC and GC-MS. And finally, the molecular mechanism responsible for growth inhibition of human carcinoma cell lines must be investigated in detail by using molecular biology and immunochemical techniques such as apoptosis.

\section{CONCLUSIONS}

IPS and EPS were produced from several mushroom strains by using either submerged and solid state fermentation. Mushroom polysaccharides have revealed highest scavenging activities for $\mathrm{Pe}(2)$, $\mathrm{Ba}$ (2), $\mathrm{Ga}(2), \mathrm{Gc}(\mathrm{r})$ and $\mathrm{Pb}(\mathrm{s})$. FTIR analysis of polysaccharides revealed absorption bands characteristics of these biological macromolecules at appropriate frequencies. IPS inhibited cell growth of HeLa cell line in the range of $16.8-27.01 \%$ for Po (s) and $\mathrm{Ga}$ (1), respectively. EPS inhibited cell growth of HeLa , A459, A431 and OE21 cell lines in the ranges of $3.08-92.2 \%, 13.8-97.4 \%, 14.7-93.8 \%$ and $25-$ $94 \%$ for II (1) and $\mathrm{Ga}(1), \mathrm{Gc}$ (1) and $\mathrm{Ga}(1), \mathrm{II}(1)$ and $\mathrm{Ga}$ (1), Le (1) and $\mathrm{Ga}$ (1), respectively. Purified preparations of EPS from Po (1) and $\mathrm{Ga}$ (1) by gel filtration chromatography confirmed growth inhibition by these biological macromolecules on A549 and OE21 cell lines.

The present results strongly suggest that most polysaccharides exhibited growth inhibition of human carcinoma cell lines in vitro which will require a detailed future research to understand its cellular mechanism of action.

\section{FINANCIAL SUPPORT}

Project UIDB/04033/2020.

\section{CONFLICT OF INTEREST}

The authors declare that there are no conflicts of interest.

\section{ACKNOWLEDGEMENTS}

This work was supported by: European Investment Funds by FEDER/COMPETE/POCI- Operacional Competitiveness and Internacionalization Programme, under Project POCI-01-0145-FEDER-006958 and National Funds by FCT - Portuguese Foundation for Science and Technology, under the project UID/AGR/04033/2020.

\section{ABBREVIATIONS}
AA = Ascorbic Acid
$\mathrm{Ba}=$ Bjerkandera adusta 


$$
\begin{aligned}
& \text { BRM = Biological Response Modifier } \\
& \text { EPS = Extracellular polysaccharides } \\
& \mathrm{f}=\text { fruiting bodies of grown mushrooms } \\
& \text { Ga = Ganoderma apllanatum } \\
& \text { Gc = Ganoderma carnosum } \\
& \text { II = Irpex lacteus } \\
& \text { IPS = Intracellular polysaccharides } \\
& \text { Le = Lentinula edodes } \\
& \text { MTT = 3-(4,5-dimethylthiazol-2-yl)-2,5- } \\
& \text { diphenyltetrazolium bromide } \\
& \text { NBT = Nitro-Blue Tetrazolium } \\
& \mathrm{Pb} \quad=\text { Piptoporus betulinus } \\
& \mathrm{Pe} \quad=\text { Pleurotus eryngii } \\
& \text { PMS = phenazine methosulphate } \\
& \text { Po = Pleurotus ostreatus } \\
& r \quad=\text { medium with rice husks } \\
& \mathrm{s} \quad=\text { medium with straw } \\
& \text { SO = Superoxide anion } \\
& 1=\text { Culture medium } 1 \\
& 2=\text { Culture medium } 2
\end{aligned}
$$

\section{REFERENCES}

[1] Zhang Y, Geng W, Shen Y, Wang Y, Dai Y-C. Edible Mushroom Cultivation for Food Security and Rural Development in China: Bio-Innovation, Technological Dissemination and Marketing. Sustainability 2014; 6: 29612973. https://doi.org/10.3390/su6052961

[2] Novak M, Vetvicka V. $\beta$-Glucans, History, and the Present: Immunomodulatory Aspects and Mechanisms of Action. J Immunotoxicol 2008; 5: 47-57. https://doi.org/10.1080/15476910802019045

[3] Wasser SP, Medicinal Mushroom Science: Current Perspectives, Advances, Evidences, and Challenges. Biomed J 2014; 37: 345-356. https://doi.org/10.4103/2319-4170.138318

[4] Chang R. Bioactive Polysaccharides from Traditional Chinese Medicine Herbs as Anticancer Adjuvants. The Journal of Alternative and Complementary Medicine 2002; 8: 559-565.

https://doi.org/10.1089/107555302320825066

[5] Chen Y, Yao F, Ming K, Wang D, Hu Y, Liu J. Review Polysaccharides from Traditional Chinese Medicines:
Extraction, Purification, Modification, and Biological Activity. Molecules 2016; 21: 1705.

https://doi.org/10.3390/molecules21121705

Ayeka PA. Potential of Mushroom Compounds as Immunomodulators in Cancer Immunotherapy: A Review article. Evidence-Based Complementary and Alternative Medicine 2018; Article ID 7271509, 9 pages. https://doi.org/10.1155/2018/7271509

Chen J, Seviour R. Medicinal importance of fungal $\beta$ $(1 \rightarrow 3),(1 \rightarrow 6)$-glucans. Mycol Res 2007; 111: 635-652. https://doi.org/10.1016/j.mycres.2007.02.011

Poride Production by Submerged and Solid-State Cultures from Several Medicinal Higher Basidiomycetes. International Journal of Medicinal Mushrooms 2013; 15: 71-79. https://doi.org/10.1615/IntJMedMushr.v15.i1.80

Fraga I, Coutinho J, Bezerra RM, Dias AA, Marques G, Nunes FM. Influence of culture medium growth variables on Ganoderma lucidum exopolysaccharides structural features. Carbohydrate Polymers 2014; 11: 936-946. https://doi.org/10.1016/j.carbpol.2014.05.047

Ruthes AC, Carbonero ER, Córdova MM, Baggio $\mathrm{CH}$, Santos ARS, Sassaki GL, Cipriani TR, Gorin PAJ, lacomini M. Lactarius rufus $(1 \rightarrow 3),(1 \rightarrow 6)-\quad \beta$-D-glucans: Structure, antinociceptive and anti-inflammatory effects. Carbohyd Polym 2013; 94: 129-136. https://doi.org/10.1016/j.carbpol.2013.01.026

Smiderle FR, Carbonero ER, Mellinger CG, Sassaki GL, Gorin PAJ, Lacomini M. Structural characterization of a polysaccharide and a $\beta$-glucan isolated from the edible mushroom Flammulina velutipes. Phytochemistry 2006; 67 : 2189-2196.

https://doi.org/10.1016/j.phytochem.2006.06.022

[12] Cao X, Liu J-L. Yang W. Hou X. Li Q-J. Antitumor activity of polysaccharide extracted from Pleurotus ostreatus mycelia against gastric cancer in vitro and in vivo. Molecular Medicine Reports 2015; 12: 2383-2389. https://doi.org/10.3892/mmr.2015.3648

[13] Uddin PK. MM, Islam MS, Pervin R, Dutta S, Talukder RI Rahman M. Optimization of extraction of antioxidant polysaccharide from Pleurotus ostreatus (Jacq.) P. Kumm and its cytotoxic activity against murine lymphoid cancer cell line. PLoS ONE 2019; 14: e0209371. https://doi.org/10.1371/journal.pone.0209371

[14] Zhang Y, Liu W, Xu C, Huang W, He P. Characterization and Antiproliferative Effect of Novel Acid Polysaccharides from the Spent Substrate of Shiitake Culinary-Medicinal Mushroom Lentinus edodes (Agaricomycetes) Cultivation. Int J Med Mushrooms 2017; 19: 395-403.

https://doi.org/10.1615/IntJMedMushrooms.v19.i5.20

[15] Wang JT, Wang Q, Han JR. Yield, polysaccharides content and antioxidant properties of the mushroom Agaricus subrufescens produced on different substrates based on selected agricultural wastes. Scientia Horticulturae 2013; 157: 84-89.

https://doi.org/10.1016/j.scienta.2013.04.006

[16] Oei P, Mushroom cultivation - Appropriate technology for mushroom growers, 3rd edition, Backhuys Publisher 2016.

[17] Silva S, Martins S, Karmali A, Rosa E. Production, purification and characterisation of polysaccharides from Pleurotus ostreatus with antitumor activity. Journal of the Science of Food and Agriculture 2012; 92: 1826-1832. https://doi.org/10.1002/jsfa.5560

[18] Bradford MM. A rapid and sensitive method for the quantitation of microgram quantities of protein utilizing the principle of protein-dye binding. Anal Biochem 1976; 72: 248254.

https://doi.org/10.1016/0003-2697(76)90527-3 
[19] Cicco N, Lanorte MT, Paraggio M, Viggiano M, Lattanzio V. A reproducible, rapid and inexpensive Folin-Ciocalteu micromethod in determining phenolics of plant methanol extracts. Microchemical Journal 2009; 91: 107-110. https://doi.org/10.1016/j.microc.2008.08.011

[20] Robak J, Gryglewski RJ. Flavonoids Are Scavengers of Superoxide Anions. Biochemical Pharmacology 1988; 37: 837-841. https://doi.org/10.1016/0006-2952(88)90169-4

[21] Osinska-Jaroszuk M, Jarosz-Wilkołazka A, Jaroszuk-Siciseł J, Szałapata K, Nowak A, Jaszek M, Ozimek E, Majewska M. Extracellular polysaccharides from Ascomycota and Basidiomycota: production conditions, biochemical characteristics, and biological properties. World J Microbiol Biotechnol 2015; 31: 1823-1844. https://doi.org/10.1007/s11274-015-1937-8

[22] Berovic M, Habijanic J, Boh B, Wraber B, Petravic-Tominac V. Production of Lingzhi or Reishi medicinal mushroom, Ganoderma lucidum (W.Curt.:Fr.) P. Karst. (higher Basidiomycetes), biomass and polysaccharides by solid state cultivation. Int J Med Mushrooms 2012; 14: 513-520. https://doi.org/10.1615/IntJMedMushr.v14.i5.100

[23] Sun C, Wang JW, Fang L, Gao XD, Tan RX. Free radical scavenging and antioxidant activities of EPS2, an exopolysaccharide produced by a marine filamentous fungus Keisskeriella sp. YS 4108. Life Sciences 2004; 75: 10631073.

https://doi.org/10.1016/j.lfs.2004.02.015

[24] Cui J, Goh KKT, Archer R, Singh H. Characterisation and bioactivity of protein-bound polysaccharides from submerged culture fermentation of Coriolus versicolor $\mathrm{Wr}-74$ and ATCC20545 strains. J Ind Microbiol Biotechnol 2007; 34: 393-402. https://doi.org/10.1007/s10295-007-0209-5

[25] Synytsya A, Mícková K, Synytsya A, Jablonsky I, Spevácek $\mathrm{J}$, Erban $\mathrm{V}$, et al. Glucans from fruit bodies of cultivated mushrooms Pleurotus ostreatus and Pleurotus eryngii: Structure and potential prebiotic activity. Carbohydrate Polymers 2009; 76: 548-556. https://doi.org/10.1016/j.carbpol.2008.11.021

[26] Radzki W, Kalbarczyk J. Water soluble polysaccharides content in three species of edible and medicinal mushrooms: Lentinula edodes, Pleurotus ostreatus, Agaricus blazei. Kerva Polonica 2010; 56: 31-38.

[27] Kozarski M, Klaus A, Niksíc M, Vrvic MM, Todorovic N, Jakovljevic D, Griensven LJ. Antioxidative activities and chemical characterization of polysaccharide extracts from the widely used mushrooms Ganoderma applanatum, Ganoderma lucidum, Lentinus edodes and Trametes versicolor. Journal of Food Composition and Analysis 2012; 26: 144-153. https://doi.org/10.1016/j.jfca.2012.02.004

[28] Wang X, Chen X, Qi Z, Liu X, Li W, Wang S. A study of Ganoderma lucidum spores by FTIR microspectroscopy. Spectrochimica Acta 2012; 91: 285-289. https://doi.org/10.1016/j.saa.2012.02.004

[29] Roca-Lema D, Martinez-Iglesias O, Fernández de Ana Portela C, Rodríguez-Blanco A, Valladares-Ayerbes M, DíazDíaz A, Casas-Pais A, Prego C, Figueroa A. In vitro Antiproliferative and Anti-invasive Effect of Polysaccharide-rich Extracts from Trametes Versicolor and Grifola Frondosa in Colon Cancer Cells. Int J Med Sci 2019; 16: 231-240. https://doi.org/10.7150/ijms.28811

[30] Zhang L, Li CG, Liang H, Reddy N. Bioactive Mushroom Polysaccharides: Immunoceuticals to Anticancer Agents. J Nutraceuticals Food Sci 2017; 2: 1-5.

[31] Friedman M. Mushroom Polysaccharides: Chemistry and Antiobesity, Antidiabetes, Anticancer, and Antibiotic Properties in Cells, Rodents, and Humans. Foods 2016; 5: 80. https://doi.org/10.3390/foods5040080

DOI: http://dx.doi.org/10.30683/1929-2279.2019.08.05

(c) 2019 Martinho and Karmali; Licensee Neoplasia Research.

This is an open access article licensed under the terms of the Creative Commons Attribution Non-Commercial License (http://creativecommons.org/licenses/by-nc/3.0/) which permits unrestricted, non-commercial use, distribution and reproduction in any medium, provided the work is properly cited. 